\title{
Correction to: Clinical practice recommendations for the diagnosis and management of Alport syndrome in children, adolescents, and young adults-an update for 2020
}

\author{
Clifford E. Kashtan ${ }^{1} \cdot$ Oliver Gross ${ }^{2}$
}

Published online: 12 January 2021

(C) IPNA 2021

\section{Correction to: Peadtr Nephr} https://doi.org/10.1007/s00467-020-04819-6

In our recent paper "Clinical Practice Recommendations for the Diagnosis and Management of Alport Syndrome in Children, Adolescents and Young Adults - An Update for 2020" [1] the definition of microalbuminuria is misstated as a urine microalbumin-creatinine ratio of $30 \mathrm{mg} / \mathrm{mg}$. The correct value is $30 \mathrm{mg} / \mathrm{g}$. We apologize for this error.

\section{References}

1. Kashtan CE, Gross O (2020) Clinical practice recommendations for the diagnosis and management of Alport syndrome in children, adolescents, and young adults-an update for 2020 . Pediatr Nephrol. https://doi.org/10.1007/s00467-020-04819-6.

Publisher's note Springer Nature remains neutral with regard to jurisdictional claims in published maps and institutional affiliations.

The online version of the original article can be found at https://doi.org/ 10.1007/s00467-020-04819-6

Clifford E. Kashtan

kasht001@umn.edu

1 Department of Pediatrics, Division of Pediatric Nephrology, University of Minnesota Medical School, 2450 Riverside Avenue, Minneapolis, MN 55454, USA

2 Department of Nephrology and Rheumatology, University Medical Center Goettingen, Goettingen, Germany 